\title{
Dentoalveolar Procedures in Immune Thrombocytopenia; Systematic Review and an Institutional Guideline
}

\author{
Wobke E. M. van Dijk ${ }^{1}$ (1) \\ Robert J. J. van Es ${ }^{2(1)}$ Maria E. P. Correa ${ }^{3}$ Roger E. G. Schutgens ${ }^{1(1)}$
}

Karin P. M. van Galen ${ }^{1}$ (1)

${ }^{1}$ Center for Benign Hematology, Thrombosis and Hemostasis, Van

Address for correspondence Wobke E. M. van Dijk, MD, Department Creveldkliniek, University Medical Center Utrecht, Utrecht, The Netherlands

2 Department of Oral and Maxillofacial Surgery, University Medical of Hematology, Van Creveldkliniek, University Medical Center Utrecht, Office C.01.428, P.O. Box 85500, 3508 GA Utrecht, The Center Utrecht, Utrecht, The Netherlands

${ }^{3}$ Oral Medicine Ambulatory, Hematology and Hemotherapy Center, Netherlands (e-mail: w.e.m.vandijk-16@umcutrecht.nl).

University of Campinas, Campinas, Sao Paulo, Brazil

TH Open 2021;5:e489-e502.

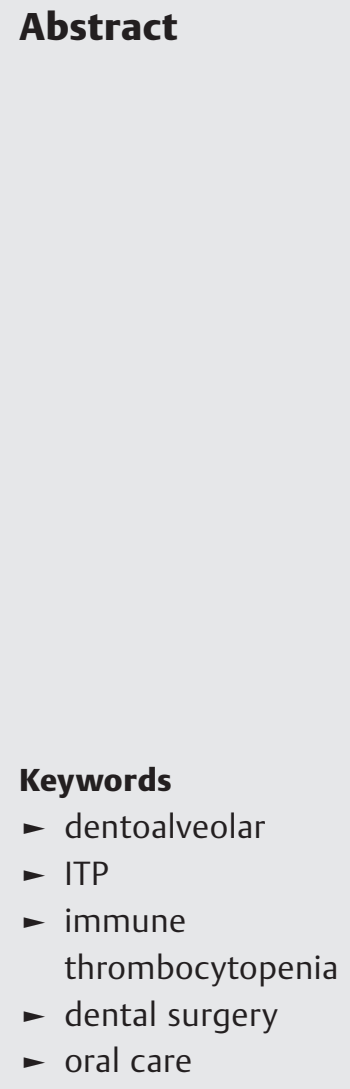

Background Dentoalveolar procedures in immune thrombocytopenia (ITP) pose a risk of bleeding due to thrombocytopenia and infection due to immunosuppressive treatments. We aimed to systematically review the safety and management of dentoalveolar procedures in ITP patients to create practical recommendations.

Methods PubMed, Embase, Cochrane, and Cinahl were searched for original studies on dentoalveolar procedures in primary ITP patients. We recorded bleeding- and infection-related outcomes and therapeutic strategies. Clinically relevant bleeding was defined as needing medical attention.

Results Seventeen articles were included, of which 12 case reports/series. Overall, the quality of the available evidence was poor. Outcomes and administered therapies (including hemostatic therapies and prophylactic antibiotics) were not systematically reported. At least 73 dentoalveolar procedures in 49 ITP patients were described. The range of the preoperative platelet count was 2 to $412 \times 10^{9} / \mathrm{L}$. Two clinically relevant bleedings (2\%) were reported in the same patient of which one was life-threatening. Strategies used to minimize the risk of bleeding were heterogeneous and included therapies to increase platelet count, antifibrinolytics, local measures, and minimally invasive techniques. Reports on the occurrence of bleedings due to anesthetics or infection were lacking.

Conclusion Based on alarmingly limited data, clinically relevant bleedings and infections after dentoalveolar procedures in ITP patients seem rare. Awaiting prospective and controlled studies to further evaluate these risks and the efficacy of therapeutic interventions, we provided our institutional guideline to guide the management of dentoalveolar procedures in ITP patients. received

February 18, 2021

accepted after revision

September 7, 2021
DOI https://doi.org/

10.1055/a-1641-7770.

ISSN 2512-9465. (c) 2021. The Author(s).

This is an open access article published by Thieme under the terms of the Creative Commons Attribution License, permitting unrestricted use, distribution, and reproduction so long as the original work is properly cited. (https://creativecommons.org/licenses/by/4.0/)

Georg Thieme Verlag KG, Rüdigerstraße 14, 70469 Stuttgart, Germany 


\section{Introduction}

Oral health care is an important part of general health. Dentoalveolar procedures, which include any surgical or nonsurgical oral or dental procedure, pose a risk of bleeding. ${ }^{1}$ Platelets play a crucial role in maintaining hemostasis in the alveolar crest and the well-vascularized oral mucosa. ${ }^{2,3}$ In immune thrombocytopenia (ITP), the risk of bleeding is therefore increased. ${ }^{4}$ ITP is a disorder in which autoantibodies destruct platelets and impair platelet production, leading to persistent thrombocytopenia $\left(<100 \times 10^{9} / \mathrm{L}\right.$ platelets). 5,6 Treatments for ITP focus on inhibiting the immune response or increasing platelet production. Complete (spontaneous) remission is possible ${ }^{6}$ but (severe) thrombocytopenia remains a problem during the acute phase, relapses, and in refractory patients. ${ }^{7}$ Furthermore, the platelet function might also be affected, resulting sometimes in an unpredictable bleeding tendency. ${ }^{8}$ In thrombocytopenic patients (due to any etiology), the risk of postoperative bleeding after dentoalveolar procedures is approximately $4.9 \%,{ }^{9}$ five times higher than the 0.2 to $1.4 \%$ in healthy individuals. ${ }^{10,11}$

Postoperative bleeding after dentoalveolar procedures can vary from being inconvenient if there is a need for reassessment, discomfort, or infection of the hematoma of being life-threatening and if the bleeding involves the floor of the mouth and thereby obstructs the upper airway. Few types of procedures pose a significant bleeding risk, but risks vary largely as per procedure. ${ }^{12,13}$ For example, single extractions and limited endodontic surgery are generally accepted as low-risk, while multiple extractions, especially upper molars, and extensive invasive osseous surgery are considered high risk. ${ }^{1,12,13}$ For many procedures, the exact bleeding risk is unknown, and also depends on other factors such as the presence of periodontal disease, age, and comorbidity of the patient. . $^{914-18}$

There are no guidelines to support dental professionals and hematologists in the management of dentoalveolar procedures in ITP patients. Methods to prevent postoperative bleeding in thrombocytopenic patients include local hemostatic techniques (primary closure, minimally traumatizing techniques, the use of hemostatic sponges, and fibrin sealants), antifibrinolytics, and increasing the platelet count. As minimal platelet count for invasive dentoalveolar procedures in thrombocytopenic patients of any etiology, a count of $>50 \times 10^{9} / \mathrm{L}$ has previously been recommended to avoid bleeding, ${ }^{1,13,14,19,20}$ although low-risk procedures might be safely performed at $>30 \times 10^{9} / \mathrm{L}$ and routine noninvasive dentistry at $>10 \times 10^{9} / \mathrm{L}^{12,21,22}$ However, these recommendations are not validated, do not distinguish specific dentoalveolar procedures, are generally not specific for ITP, and are based on expert opinion or consensus. In addition, no evidence-based guidelines are available for the use of antifibrinolytics and local hemostatic techniques in this patient category.

Of note, ITP patients might be at risk of infections in addition to bleeding. First, because ITP treatment is often based on immunosuppression. Particularly corticosteroids are known to inhibit the immune response, as well as wound healing, which is essential to prevent infectious problems. $^{23,24}$ Furthermore, ITP patients are prone to having poor oral hygiene due to bleeding complaints related to tooth brushing. ${ }^{25,26}$ Lastly, platelets play a (not fully explored) role in immune responses. ${ }^{27}$ The exact risk of infection is unknown. No guidelines advise on the use of antibiotic prophylaxis for dentoalveolar procedures in ITP patients.

We systematically reviewed the available literature on the risk of dentoalveolar procedures in primary ITP, with respect to bleeding and infection and the effectiveness of management strategies. Since dentoalveolar procedures in ITP patients are a daily practice, we aimed to provide guidelines to guide dental professionals and hematologists in the management.

\section{Methods}

The databases, that is, PubMed, Embase, Cochrane, and Cinahl, were searched up to April 23, 2020. The search strategy combined all key terms for ITP, dental/oral/tooth and procedures/surgery (see Search Details in -Supplementary Material for the detailed search). The references of relevant articles were searched for any additional papers. All original studies in English or Dutch assessing dentoalveolar procedures in adult and pediatric patients with known ITP at the time of procedure were included if the full text was available. We excluded papers about ITP secondary to an underlying disease, as well as papers about major maxillofacial surgery or exclusively orthodontic procedures. Data were extracted using a standardized form and included information about the ITP specifics; procedure; anesthetic methods; pre-, peri-, and postoperative preventive strategies; and bleeding- and infection-related outcomes. The included articles were critically appraised on the quality of the available data and, if applicable, on the risk of bias, using the Cochrane Robins-I tool.

To include all potentially relevant evidence, we included any article where the patient(s) was/were regarded to have ITP, independent of how the diagnosis was made. Furthermore, data for adults and children were reported separately; if data on age were missing, the data are reported in the adults section.

Dentoalveolar procedures were defined as any surgical or nonsurgical oral or dental procedure except major maxillofacial surgery or exclusively orthodontic procedures. The search included a variety of both surgical and nonsurgical dentoalveolar procedures with a potential bleeding risk, such as tooth extractions, submucosal scaling, and periodontal, endodontic, restorative, and orthodontic treatment. An explanation of specific dental procedures and terminology is provided in - Supplementary Table S1.

Any reported bleeding episode was recorded and categorized according to the American College of Chest Physicians guidelines. ${ }^{28}$ A bleeding was considered not clinically relevant if the bleeding was self-limiting (e.g., with local pressure) and did not require medical attention. Clinically relevant bleedings were divided into major if the bleeding required transfusion (of $\geq 2$ units) of red blood cells, and 
nonmajor if the bleeding was not major but required medical attention (e.g., application of wound dressing or additional sutures). We assumed that no clinically relevant bleeding occurred if it was not reported in the paper. If possible, data were recorded separately for each individual dentoalveolar procedure but in some papers, only summarized data was available.

Any given therapies to decrease the risk of bleeding were recorded. These included antifibrinolytic therapies and local/surgical measures (e.g., fibrin sealants and splints), as well as therapies aiming to increase the platelet count preprocedurally, and any ITP medication that patients were on independent of the dentoalveolar procedure.

We provided the institutional guideline as used in the Van Creveldkliniek, expert center on benign hematology and hemostasis of the University Medical Center Utrecht, the Netherlands. This guideline is based on the available evidence and, where the evidence proved to be limited, the clinical experience from the Van Creveldkliniek.

\section{Results}

The search yielded 424 unique articles of which 14 articles were selected (-Fig. 1). Additionally, by searching references, three extra studies were found that all assessed patients with a variety of bleeding disorders of whom a few had ITP. Five articles were excluded because the full text was unavailable. In total, 17 articles were included in our review. The details of the selected studies are reported in - Table 1. Twelve articles were case reports/series, four were prospective one-arm studies that included a subset of ITP patients, and one was a retrospective cohort study. Only one article clearly reported criteria for the ITP diagnosis.

-Fig. 1 shows article screening procedure through a flowchart.

In this review, a total of 73 dentoalveolar procedures were performed in 49 ITP patients of which 13 of 73 (18\%) procedures in 6 of 49 (12\%) children (-Table 1). Critical appraisal revealed that the quality of the overall available evidence was poor (-Supplementary Tables S2, S3 and S4), partly because the majority of articles comprised case reports. The four prospective studies and one retrospective cohort study had a medium-to-high risk of bias. Of the prospective studies, three assessed the effectiveness of local hemostatic measures ${ }^{29-31}$ and one of aminocaproic acid. ${ }^{32}$ None of the studies had a control group.

\section{Bleeding Complications}

Overall, two clinically relevant bleedings, - one major and one nonmajor, were reported after 2 of 60 (3\%) procedures in adults, both in the same patient (1/43 [2\%] of the adults). ${ }^{33}$ None of the children experienced a clinically relevant bleeding. The first bleeding, nonmajor, occurred after extraction of the left mandibular first molar, at a platelet count of $35 \times 10^{9} / \mathrm{L}$. It persisted for 1 week and was controlled by extra suturing. The second bleeding, major, occurred after dental



Fig. 1 Flowchart article screening. 


\begin{tabular}{|c|c|c|c|c|c|c|c|c|c|c|c|c|c|c|c|c|c|c|c|c|}
\hline & $\frac{\alpha}{z}$ & \multicolumn{2}{|r|}{$\sum$} & 2 & \multicolumn{2}{|c|}{$\frac{\alpha}{2}$} & $\frac{g}{2}$ & \multicolumn{2}{|r|}{2} & $\begin{array}{l}2 \\
Z \\
z \\
z\end{array}$ & \multicolumn{2}{|c|}{\begin{tabular}{l|l}
$\frac{\alpha}{z}$ & $\stackrel{2}{z}$
\end{tabular}} & $\frac{2}{z}$ & $\stackrel{\text { 管 }}{2}$ & 告 & & 兴 & $\frac{2}{z}$ & & \multirow{8}{*}{ 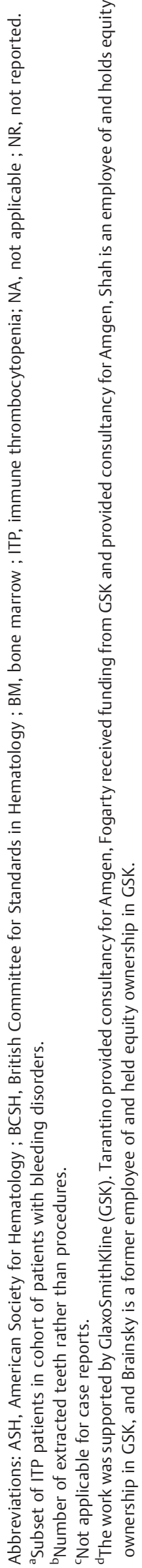 } \\
\hline 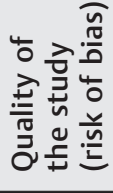 & 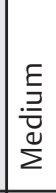 & 氡 & $\Sigma$ & 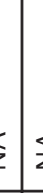 & 告 & $\mathbb{z}$ & $\bar{z}$ & $\Sigma$ & $\Sigma$ & $\Sigma$ & $\Sigma$ & 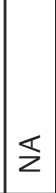 & 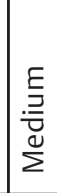 & $\Sigma$ & 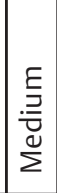 &  & $\Sigma$ & 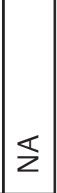 & & \\
\hline  & $\begin{array}{l}\frac{0}{0} \\
\frac{\pi}{2} \\
\frac{\pi}{2} \\
\frac{0}{2}\end{array}$ & 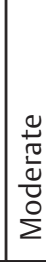 & O & & & 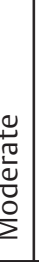 & $\begin{array}{l}\frac{ \pm}{0} \\
\frac{0}{0} \\
\frac{0}{0} \\
0\end{array}$ & $\begin{array}{l}1 \\
\vdots \\
\end{array}$ & 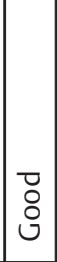 & $\begin{array}{l}\square \\
\\
ن\end{array}$ & $\begin{array}{l}\overrightarrow{0} \\
\stackrel{\circ}{\circ}\end{array}$ & $\begin{array}{l}\overrightarrow{0} \\
0 \\
0\end{array}$ & $\begin{array}{l}\frac{0}{0} \\
\frac{\pi}{2} \\
\frac{0}{0} \\
\frac{0}{2}\end{array}$ & $\begin{array}{l}0 \\
0 \\
0 \\
0\end{array}$ & $\mid \begin{array}{l}\frac{\pi}{0} \\
\frac{\pi}{2} \\
\frac{0}{0} \\
\Sigma \\
\Sigma\end{array}$ &  & $\begin{array}{l}0 \\
0 \\
0 \\
0\end{array}$ & 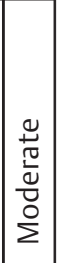 & & \\
\hline 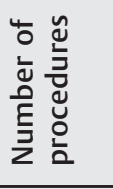 & 6 & $\tau$ & $\sim$ & & n & - & - & - & $m$ & - & $\tau$ & $m$ & $\mp$ & - & $\stackrel{\sim}{\sim}$ & $m$ & - & $m$ & & \\
\hline 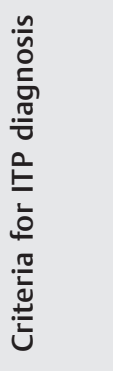 & $\frac{2}{z}$ & $\frac{u}{z}$ & $\frac{u}{z}$ & & & $\frac{2}{z}$ & 些 & $\frac{⿱}{z}$ & $\frac{\mathrm{a}}{z}$ & $\frac{\mathrm{v}}{z}$ & 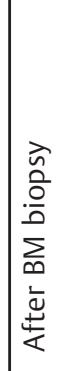 & 笲 & 哭 & 笠 & 誉 &  & 笲 & 学 & & \\
\hline $\begin{array}{l}\text { 느 } \\
\text { है }\end{array}$ &  &  & $\begin{array}{l}\frac{0}{3} \\
\text { - } \\
-\end{array}$ & & & $\begin{array}{l}\frac{5}{5} \\
\frac{5}{\pi} \\
- \\
\end{array}$ & $\begin{array}{l}\frac{T}{5} \\
\frac{0}{0} \\
\square \\
\square \\
\end{array}$ & $\begin{array}{l}\frac{\pi}{3} \\
\frac{7}{0}\end{array}$ & \begin{tabular}{|l|}
$\frac{y}{3}$ \\
0 \\
0 \\
- \\
\end{tabular} & \begin{tabular}{|l|}
$\frac{T}{5}$ \\
$\frac{7}{0}$ \\
0 \\
- \\
\end{tabular} & $\begin{array}{l}\frac{5}{5} \\
\frac{0}{0} \\
- \\
\end{array}$ &  & $\begin{array}{l}\widehat{\widehat{v}} \\
\underline{\underline{\omega}} \\
\widetilde{0}\end{array}$ & 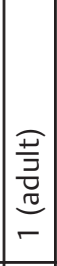 & $\begin{array}{l}\widehat{\widetilde{\alpha}} \\
\underline{\underline{z}} \\
-\end{array}$ & $\frac{\sqrt{\frac{\pi}{3}}}{\frac{\vec{n}}{\sqrt[n]{n}}}$ &  & 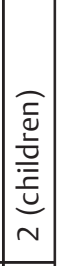 & & \\
\hline$\frac{\bar{v}}{\bar{y}}$ & 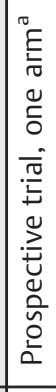 & 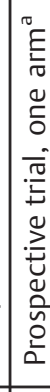 & 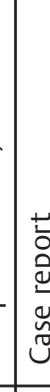 & & & 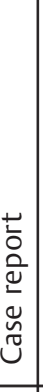 & 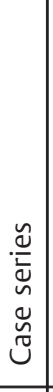 & 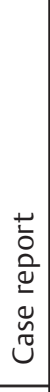 &  & 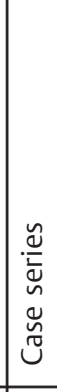 & 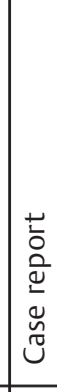 &  & 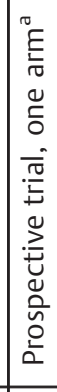 & 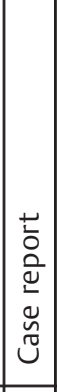 & 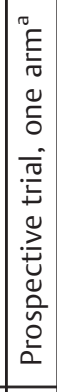 &  & 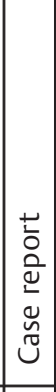 & 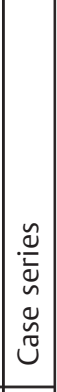 & & \\
\hline 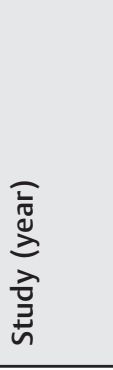 & 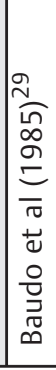 &  & ఫ & כ. & & 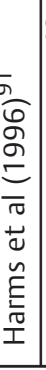 &  &  & 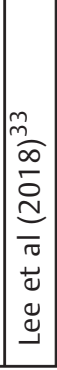 & 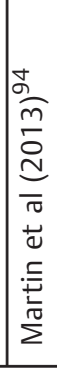 & 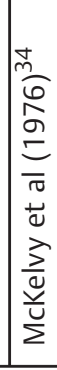 & $\mid$ & 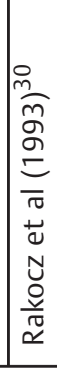 & 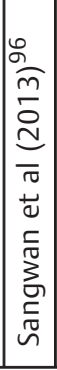 & 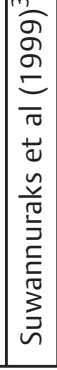 & 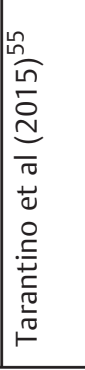 & 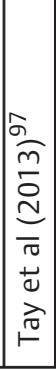 & 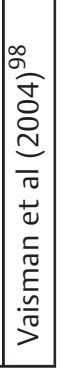 & & \\
\hline
\end{tabular}


implantation of that same molar. It happened at a platelet count of $22 \times 10^{9} / \mathrm{L}$ and presented with submandibular swelling within 24 hours after the procedure. The bleeding was complicated by an airway obstruction for which the patient received an emergency tracheostomy and a decrease in hemoglobin of $3 \mathrm{~g} / \mathrm{dL}$ for which the patient received red blood cell transfusions. No therapies were administered to increase the platelet count. The authors failed to mention whether preventive hemostatic measures were applied.

-Tables 2 and $\mathbf{3}$ summarize which procedures were reported in the selected articles at which platelet count for adults and children separately and whether a bleeding occurred. The largest proportion of the procedures comprised dental extractions (29/73 [40\%]), mostly regular dental extractions in adults (25/29 [86\%]). In 5 of 29 (17\%), the extraction was performed in a child and combined with another procedure. No bleeding occurred in the 14 of 73 (19\%) procedures where the platelet count was $<20 \times 10^{9} / \mathrm{L}$. Procedures with a platelet count $<20 \times 10^{9} / \mathrm{L}$ were performed mainly in adults; 12 procedures were specifically minimally invasive. The only procedure performed in a child at this low platelet count was because of the patient was refractory to all available treatments. Of note, for 38 of 73 (52\%) procedures, only summarized data were available on the platelet count before the procedure and the outcomes.

Therapies aimed to increase the platelet count were given prior to 10 of 60 (17\%) procedures in adults and 4 of 13 (31\%) in children (-Tables 2 and $\mathbf{3}$ ). The initial platelet counts in these patients ranged from 2 to $48 \times 10^{9} / \mathrm{L}$. The most common strategies were steroids and intravenous immunoglobulins (IVIg), with or without platelet transfusion. Eltrombopag was only given once, in an adult, which increased the platelet count from 18 to $55 \times 10^{9} /$ L. Romiplostim was not used. Doses and treatment durations (if reported) can be found per individual procedure in -Supplementary Table S7. Despite therapy, the platelet count was still $<50 \times 10^{9} / \mathrm{L}$ at the time of two procedures but no bleeding occurred. These procedures were reendodontic treatment combined with incision of a subperiosteal abscess using laser treatment (platelet count $2 \times 10^{9} / \mathrm{L}$ after treatment with intravenous prednisone) and dental extraction combined with mandibular fenestration (platelet count $43 \times 10^{9} / \mathrm{L}$ after treatment with IVIg and platelet transfusion).

In most procedures (46/60 [77\%]) in adults, $2 / 13$ [15\%] in children), no therapy was given to increase the platelet count (not reported in 7 and 54\%, respectively). In the group with a platelet count of $<20 \times 10^{9} / \mathrm{L}$, no therapy was given prior to the 12 minimally invasive dental extractions after which no bleeding occurred. In the adult group with a platelet count between 20 and $50 \times 10^{9} / \mathrm{L}$, no therapy was given prior to 2 of 2 procedures in the same patient after which the above mentioned clinically relevant bleeding events occurred.

With respect to hemostatic strategies, the use of antifibrinolytics or surgical hemostatic measures was only reported in 22 of 60 (37\%) of the procedures in adults and 1 of $13(8 \%)$ of the procedures in children. The combination of strategies was heterogeneous, as well as the route of admin- istration and the dosing of the antifibrinolytics, if reported at all. The specific drug was tranexamic acid in all except one procedure and was administered locally (mouthwash), orally, and/or intravenously. The details per procedure can be found in -Supplementary Table s7. None of the patients in whom any hemostatic strategy was given experienced a clinically relevant bleeding (-Supplementary Tables S5-S7).

No bleeding complications due to the anesthetics were mentioned in the articles. In 17 of 60 (28\%) of the procedures in adults and 10 of 13 (70\%) of the procedures in children, the authors mentioned the anesthetic approach, that is, local infiltration anesthesia in most (14/17 [82\%] in adults and 5/10 [50\%] in children). Regional mandibular block anesthesia was used only in one procedure in an adult, with a platelet count between 50 and $100 \times 10^{9} / \mathrm{L}$. The platelet count in relation to the anesthetic approach can be found in - Supplementary Tables S5 and S6.

\section{Infectious Complications}

Neither the occurrence nor the absence of infections was mentioned in the included studies. Only in one case with a fluctuating dose of prednisolone, a "febrile episode" was reported without any other complications. ${ }^{34}$ None of the articles reported whether antibiotic prophylaxis was administered. The use of immunosuppressive agents during the procedure was rare. In 11 of 73 (15\%) procedures, patients were known to use immunosuppressive agents. All these used steroids were either administered preoperatively to perform the procedure (six procedures; - Table 2 ) or as lowdose concomitant ITP medication (five procedures). Prednisolone was combined with cyclosporin A in three procedures. No other use of immunosuppressive agents was reported.

\section{Discussion}

This systematic review showed that little evidence on the management of dentoalveolar procedures in ITP patients is available, especially in children. The limited evidence suggests that clinically relevant bleeding complications after dentoalveolar and anesthetic procedures are rare (3\% of the procedures in adults and $0 \%$ of the procedures in children). However, no conclusions can be drawn concerning the effectiveness of different bleeding preventive strategies, nor the risk of infection.

This is the first systematic review regarding the management of dentoalveolar procedures in ITP patients. Strengths of the review are the structured and detailed overview of data, as well as the extensive search. Predefined inclusion and exclusion criteria and a standardized data-extraction form were used to minimize bias. An important limitation of the review is the low quality of the evidence and the few cases with truly low platelet counts (below the $30-50 \times 10^{9} / \mathrm{L}$ ). Furthermore, selective reporting of outcomes, as well as the absence of standardized definitions, imposes a significant risk of bias. Finally, most articles did not explain how the ITP was diagnosed which may have caused heterogeneity of the population and limited generalizability; particularly in case of accidental inclusion 


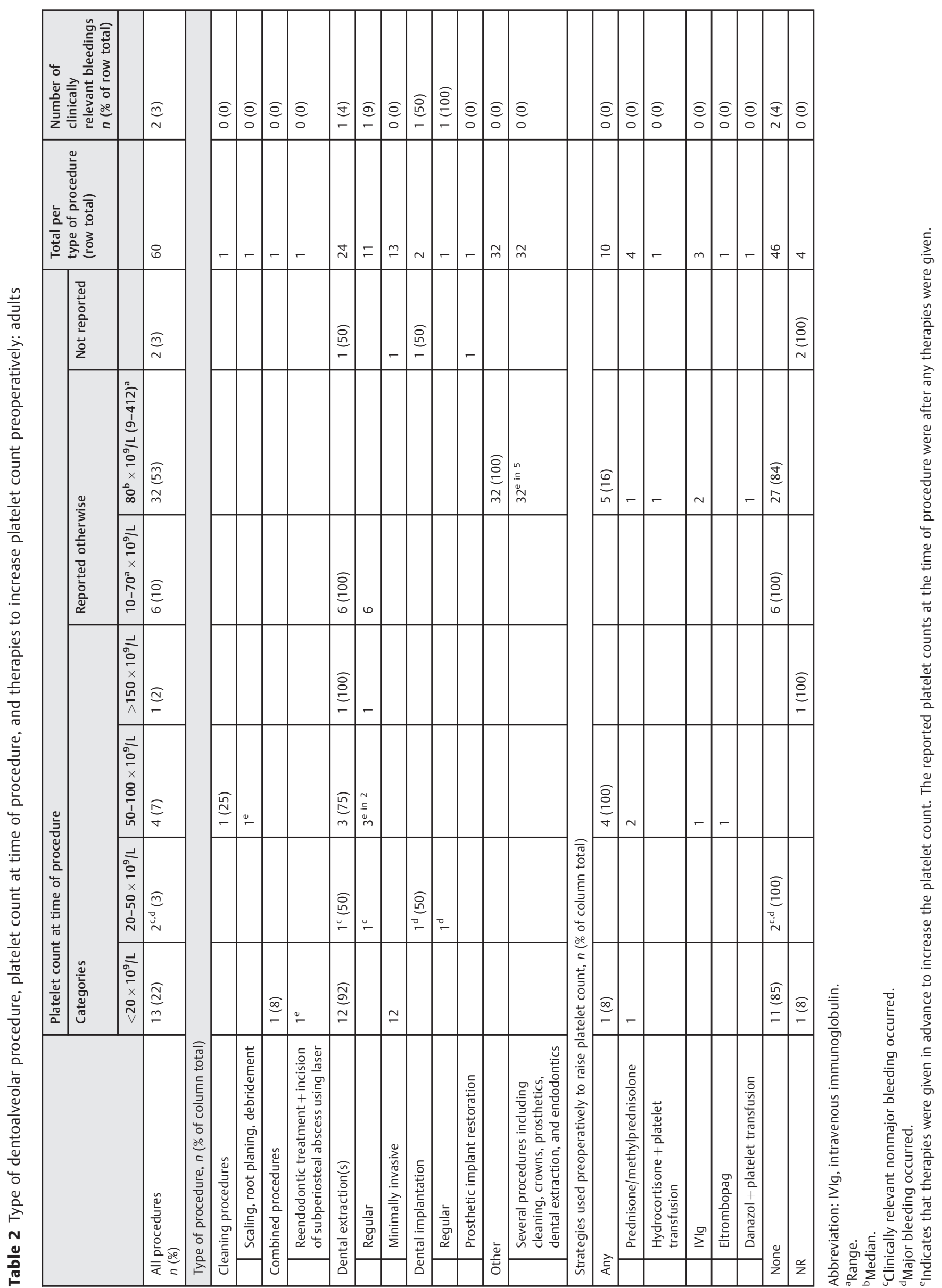




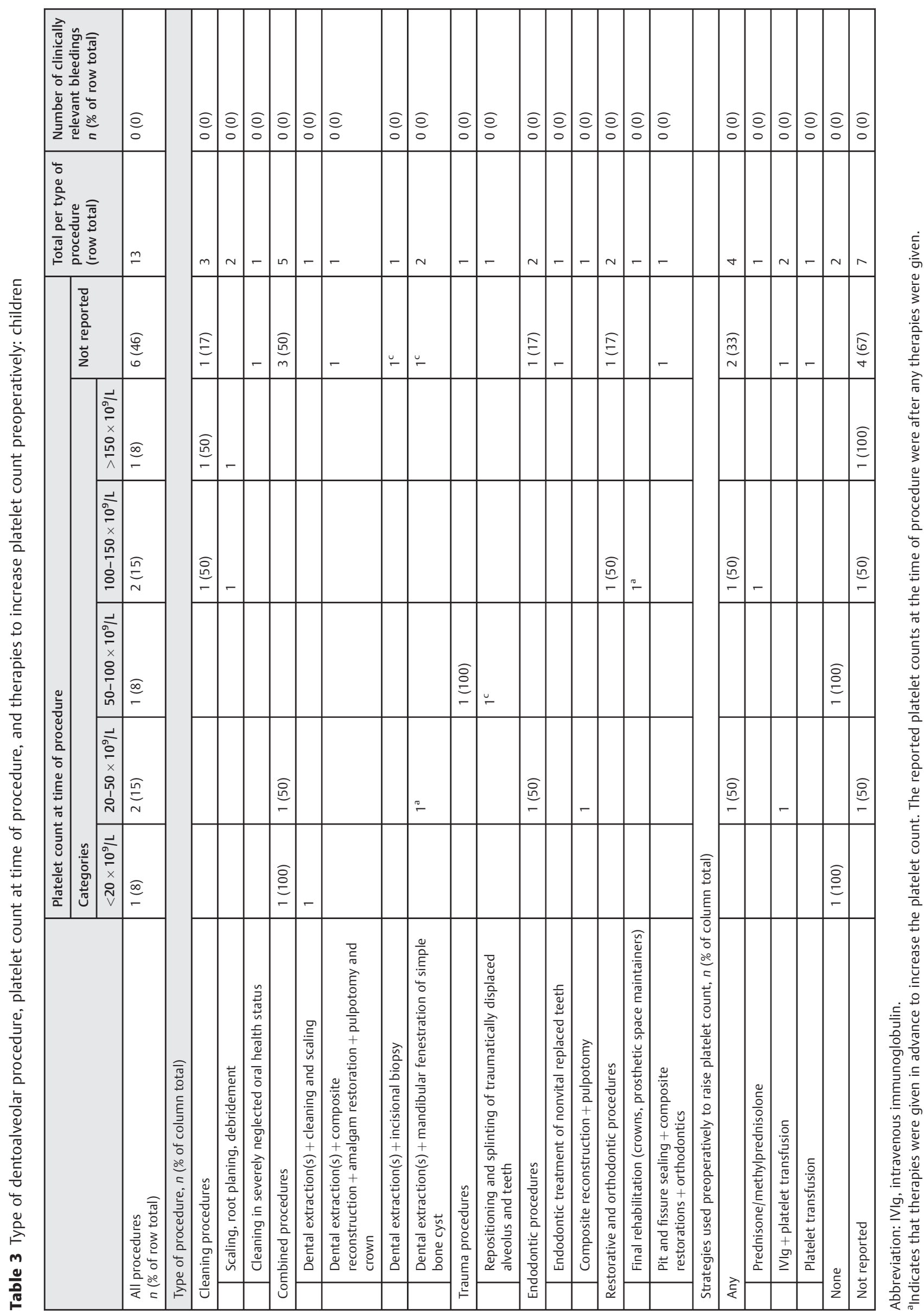


of secondary ITP patients. However, the heterogeneous population may be a better reflection of the daily clinical practice where the medical history is often limited to "has ITP."

Only two clinically relevant bleeding complications (2\%) were reported, one major and one nonmajor, both in the same patient. This suggests that the risk in ITP patients is lower than the $4.9 \%$ in thrombocytopenic patients of any etiology. ${ }^{9}$ The bleedings occurred after low bleeding risk procedures with a platelet count of 22 and $35 \times 10^{9} / \mathrm{L}$, respectively. Based on the available ITP guidelines, these platelet counts should have been relatively safe, $>1010^{9} / \mathrm{L}$ for routine noninvasive dentistry, $>30 \times 10^{9} / \mathrm{L}$ for tooth extractions and regional mandibular blocks, and $>50 \times 10^{9} /$ L for minor oral surgery. ${ }^{21}$ However, the bleeding risk is not only dependent on the platelet count ${ }^{9}$ but also on local hemostatic interventions, the administration of antifibrinolytic therapy, and the presence of personal risk factors such as the presence of predominantly mucosal rather than cutaneous bleeding, concomitant bleeding disorders or platelet abnormalities, and comorbidity. ${ }^{9,15-18,35-40}$ Unfortunately, in the studies selected for our review, information on bleeding manifestations and comorbidity was too limited to address this issue, and information on platelet abnormalities was absent altogether. Also in this particular patient, these factors were unknown but they could have played a significant role in the occurrence of the bleedings.

The risk of infection-related complications seems low, considering that none of the reviewed 118 procedures reported any. Of note, infections were not of primary interest in the included papers nor was the administration of antibiotic prophylaxis reported in any of the cases. ITP patients have several reasons for an increased risk of infection, including the use of immunosuppressants ${ }^{23,24,41-43}$ and possible issues with oral hygiene due to bleeding complaints. ${ }^{25,26}$ Prospective research is needed to evaluate the exact risk of dental infections in ITP patients and the need for antibiotic prophylaxis.

None of the reports mentioned bisphosphonate-related osteonecrosis of the jaw (BRONJ). BRONJ is a rare but serious condition triggered by invasive dentoalveolar procedures 44 and characterized by exposed jaw bone surrounded by inflamed tissue that can lead to osteolysis, pathological fractures, and fistulas. ${ }^{45}$ Since bisphosphonates are sometimes administrated to ITP patients in case of long-term corticosteroids treatments, awareness is due.

\section{Unanswered Questions and Future Research}

First and foremost, prospective studies are needed to evaluate the safety of dentoalveolar procedures in ITP patients with low platelet counts, as well as the need for and efficacy of therapeutic interventions to prevent bleeding and infection. Furthermore, to improve the individual risk assessment, other markers that predict bleeding could be of value, rather than or in addition to platelet count.

\section{Institutional Guideline}

Dentoalveolar procedures are part of daily clinical practice. There is limited evidence on how to proceed in patients with ITP. Therefore, we provide our institutional guideline which combines the preceding literature review with our clinical experience. The guideline is primarily intended for adults, particularly concerning the recommendations about raising the platelet count, and are used in our expertise center for benign hematology and hemostasis (Van Creveldkliniek, University Medical Center Utrecht, The Netherlands).

\section{Bleeding}

Measures to prevent bleeding may include appropriate planning of the procedure, pharmacological treatment to increase the platelet count and improve hemostasis, as well as and nonpharmacological interventions to achieve local hemostasis. An overview of the recommendations is depicted in the flowchart (-Fig. 2). Different aspects of this flowchart are discussed in more detail below.

To improve future research and management, a uniform classification of postoperative bleeding after dentoalveolar procedures is mandatory. As an ITP-specific classification is unavailable, we recommend the internationally accepted and widely used classification from the American College of Chest Physicians guidelines. This classification divides



Fig. 2 Flowchart to prepare dentoalveolar procedure. NSAIDs, nonsteroid anti-inflammatory drugs, TPO-RA, thrombopoietin-receptor agonists. 
bleedings into "major," "clinically relevant nonmajor," and "minor." 28 The exact definition is provided in the "Methods" section of this article.

\section{Bleeding Risk and Planning}

We divide procedures into three categories based on the bleeding risk as follows: "minimal," "low," and "high" risk. - Table 4 provides an overview in which category common dentoalveolar procedures could fall. This overview excludes major maxillofacial surgery.

Limiting the extent of the dentoalveolar procedure in patients with bleeding disorders could decrease the risk of (severe) bleeding and improve the possibilities to control any bleeding should it occur. ${ }^{1,14,46}$ In this respect, treating mandibular procedures unilaterally should be considered, particularly if the platelet count is $<50 \times 10^{9} / \mathrm{L}$, as bilateral bleeding could threaten the airway.
When a considerable bleeding risk is anticipated, it is preferable to treat the patient early in the day to allow for observation. If feasible, it might also be considered to either postpone the procedure until the ITP is more stable or in remission or to avoid surgery altogether. It should be taken into account that postponing or avoiding surgery might be an inferior option, especially since bleedings seem to occur rarely. 1

In any patient with a bleeding tendency, we advocate putting effort into obtaining optimal local hemostasis. ${ }^{9}$ Several principles have previously been recommended as mentioned below ${ }^{1,14,46}$ :

- Delicate tissue handling and application of cautery, suturing. and wound packing (e.g., bite gauze).

- Avoiding major periodontal flap procedures when possible.

Table 4 Bleeding risk of dentoalveolar procedures (excluding major maxillofacial surgery)

\begin{tabular}{|c|c|c|c|}
\hline & Minimal risk & Low risk & High risk \\
\hline Anesthesia & $\begin{array}{l}\text { Sedation techniques or } \\
\text { general anesthesia } 1\end{array}$ & $\begin{array}{l}\text { Local anesthesia (e.g., } \\
\text { infiltration, intraligamental, and } \\
\text { intrapulpal techniques) } \\
\text { Mandibular block } \\
\text { injections } 13,12,13\end{array}$ & - \\
\hline Oral hygiene & $\begin{array}{l}\text { Cleaning (sub- or } \\
\text { supragingival), pit and fissure } \\
\text { sealing }\end{array}$ & Simple and deep scaling ${ }^{12}$ & - \\
\hline $\begin{array}{l}\text { Endodontic } \\
\text { treatment }\end{array}$ & $\begin{array}{l}\text { Instrumentation not beyond } \\
\text { apical constriction }\end{array}$ & $\begin{array}{l}\text { Pulpotomy }{ }^{12,46} \\
\text { Instrumentation beyond apical } \\
\text { constriction }\end{array}$ & Apical endodontic surgery \\
\hline $\begin{array}{l}\text { Periodontal } \\
\text { treatment }\end{array}$ & - & $\begin{array}{l}\text { Subgingival scaling and root } \\
\text { planing }\end{array}$ & $\begin{array}{l}\text { Periodontal surgery } \\
\text { (curettage, (major) flap } \\
\left.\text { surgery }^{13}\right)^{a}\end{array}$ \\
\hline Tooth extractions & $\begin{array}{l}\text { Singular single-rooted tooth } \\
\text { extractions } 46,49\end{array}$ & Simple tooth extractions ${ }^{35,49,99}$ & $\begin{array}{l}>3 \text { roots or complex } \\
\text { procedures } 13\end{array}$ \\
\hline Dental implants & - & Regular procedures ${ }^{14,35,99,100}$ & Mandibular procedures ${ }^{\mathrm{a}}$ \\
\hline Oral surgery, other & - & $\begin{array}{l}\text { (Superficial) abscess } \\
\text { incision } 35,99 \\
\text { Mucosal and mucocutaneous } \\
\text { biopsies } \\
\text { Biopsies of apical lesions }{ }^{14,101}\end{array}$ & $\begin{array}{l}\text { Surgical removal of teeth } \\
\text { Deep tissue biopsies (e.g., } \\
\text { salivary glands) }\end{array}$ \\
\hline Prosthetics & $\begin{array}{l}\text { Total prosthesis, prosthetic } \\
\text { space maintainers }\end{array}$ & - & - \\
\hline $\begin{array}{l}\text { Crowns and } \\
\text { bridgework }\end{array}$ & $\begin{array}{l}\text { Uncomplicated procedures } \\
\text { with minimal gingival } \\
\text { manipulation }\end{array}$ & $\begin{array}{l}\text { Procedures requiring } \\
\text { subgingival } \\
\text { manipulation/preparation or } \\
\text { removal of dental cement }\end{array}$ & - \\
\hline $\begin{array}{l}\text { Restorative } \\
\text { dentistry (“fillings") }\end{array}$ & $\begin{array}{l}\text { Uncomplicated procedures } \\
\text { with minimal gingival } \\
\text { manipulation }\end{array}$ & $\begin{array}{l}\text { Procedures requiring gingival or } \\
\text { subgingival manipulation }\end{array}$ & - \\
\hline Orthodontics & $\begin{array}{l}\text { Non-invasive orthodontic } \\
\text { procedures }\end{array}$ & $\begin{array}{l}\text { Procedures requiring gingival or } \\
\text { subgingival manipulation }\end{array}$ & Orthodontic surgery \\
\hline $\begin{array}{l}\text { Posttraumatic } \\
\text { procedures }\end{array}$ & - & $\begin{array}{l}\text { Minimal invasive procedures } \\
\text { (e.g., repositioning and } \\
\text { splinting) }\end{array}$ & Any surgical procedure \\
\hline
\end{tabular}

${ }^{a}$ Local factors, such as concomitant periodontal disease, might increase the bleeding risk of the procedure. 
- Eliminating associated granulation tissue.

- Primary surgical closure, especially where flaps have been elevated.

The use of local hemostatic interventions (e.g., hemostatic sponges or fibrin sealants) and antifibrinolytics are recommended in ITP patients. The choice for the type of local hemostatic measures should be based on the specific circumstances and preferences of the treating oral professional, since no evidence is available in thrombocytopenic patients as to which treatment is most effective. ${ }^{35,47-50}$

\section{Increasing the Platelet Count}

As depicted in the flowchart (-Fig. 2), we recommend a minimal platelet count of more than 30 or $50 \times 10^{9} /$ L for lowor high-risk procedures, respectively; no minimal platelet count is required for minimal risk procedures ( $\mathbf{- T a b l e ~ 4}$ ). However, a higher minimal platelet count could be appropriate in the presence of other bleeding risk factors such as a notable bleeding tendency (particularly presence of mucosal bleeds such as gum- or nosebleeds), ${ }^{18}$ impaired platelet function, anticoagulants, and comorbidity. ${ }^{9,15-18}$

In practice, we check the platelet count 2 weeks prior to the procedure to allow for an intervention, if necessary. If no intervention is required and the platelet count is generally stable, no additional check is necessary; otherwise, we check the platelet count on the day of the procedure.

-Fig. 2 presents dentoalveolar procedure through flowchart.

The several therapies to boost a patient's platelet count include thrombopoietin receptor agonists (TPO-RAs) such as eltrombopag and romiplostim, IVIg, steroids, and platelet transfusion (-Fig. 2). Characteristics of the individual patient should always be considered when choosing the preoperative strategy. In general, TPO-RAs, either eltrombopag or romiplostim may be the first choice. Compared with IVIg, they are at least effective, ${ }^{51}$ more convenient, less expensive, and they have relatively few side effects. ${ }^{6,52-58}$ IVIg is an effective alternative option. Although IVIg is expensive and the patient-burden is high in terms of side effects and logistics (hospital visits), ${ }^{59-69}$ its use is well known for this indication and the time to response is relatively short. ${ }^{21,70,71}$ Steroids are cheap and often effective. However, their application should be reconsidered due to the side effects associated with even short courses of steroids including sleep disturbances, mood swings, glucose dysregulation and an increased risk of sepsis, venous thromboembolism, and fractures. ${ }^{24,72-76}$ Platelet transfusion should be reserved for acute situations and very refractory patients; the effect is usually short lived and poses a risk of transfusion-related adverse events. ${ }^{62,77}$ Although no evidence is available on this subject, based on the Dutch clinical practice, we generally suggest to start the procedure within 30 minutes after 2 units of platelets (minimal $2.5 \times 10^{11} / \mathrm{L}$ platelets per bag) have been administered. For practical reasons, a platelet count below the minimum, in this case, is regarded solely as a trigger for transfusion; the platelet count is not checked after transfusion to avoid time loss.
We recommend to not routinely check the platelet count postoperatively, unless a problem occurs. Postoperatively, the recently initiated medication can be discontinued. If the patient is already using ITP medication and the platelet levels are adequate, the treatment can be continued during the procedure. In patients using long-term low-dose steroids ( $<7.5 \mathrm{mg} /$ day), it is not necessary to increase the dose for routine dental treatment, including minor surgical dentoalveolar procedures. $^{78}$

\section{Antifibrinolytic Therapy}

With regard to antifibrinolytic therapy, we recommend the use of tranexamic acid orally (1-1.5 g two to three times daily $)^{35,49}$ which should be started several hours prior to the procedure and continued for 5 to 7 days. Antifibrinolytic therapy is contraindicated in case of severe kidney disease (estimated glomerular filtration rate $<15\left[\mathrm{~mL} / \mathrm{min} / 1.73 \mathrm{~m}^{2}\right]$ ), active thromboembolic disease, or a history of convulsions. ${ }^{75}$ In addition, antifibrinolytic agents can be used topically as a mouthwash to be rinsed gently through the mouth or soaked in a sponge if the surgical site is accessible.

\section{Analgesics}

Traditional nonsteroidal anti-inflammatory drugs (NSAIDs) inhibit the hemostatic function of platelets and should therefore be avoided in patients with thrombocytopenia. ${ }^{79-81}$ Instead, the use of opioids could be considered or coxib's (selective NSAIDs, such as celecoxib and etoricoxib), since these agents primarily inhibit cyclooxygenase 2 (COX-2) rather than COX-1, and therefore affect platelet function less.

\section{Infection, Wound Healing, and Osteonecrosis}

ITP patients potentially have an impaired wound healing and a higher risk of infection. The dental professional and/or treating physician should be aware of this possible increased risk, particularly in patients using corticosteroids or other immunosuppressive medication. There is insufficient evidence of a substantially increased infection risk to recommend the administration of prophylactic antibiotics routinely.

Vigilance is needed for osteonecrosis risk of the jaw in selected patients that had (previous) exposure to bisphosphonates. Preferably, necessary dentoalveolar procedures are performed before the start of the bisphosphonates. ${ }^{82}$

\section{Discussion of the Institutional Guideline}

The strength of this institutional guideline is that it is the only available guidance for clinical practice. Uniform practice will also enable future research regarding the safety and management of dentoalveolar procedures in ITP. A weakness of the guideline is that no formalized method was used.

As previously mentioned, no specific guidelines are available for managing dentoalveolar procedures in ITP patients. The 2003 ITP guidelines only recommend minimal platelet counts for some general procedures: $10 \times 10^{9} / \mathrm{L}$ for routine noninvasive dentistry, $>30 \times 10^{9} /$ L for tooth extractions, and regional mandibular blocks and $>50 \times 10^{9} / \mathrm{L}$ for minor oral surgery. ${ }^{21}$ These are in line with our recommendations 
in - Table 4 and - Fig. 2. These 2003 ITP guidelines do not specifically mention methods to increase the platelet count prior to dentoalveolar procedures, other than that IVIg is an appropriate treatment for this indication. The 2019 ITP guidelines do not mention dentoalveolar procedures at all nor recommend platelet counts or treatments to perform other forms of surgery. ${ }^{6}$ Lastly, we checked guidelines for oral and dental management in patients with myelodysplastic syndrome and acute myeloid leukemia. ${ }^{83}$ These advise a platelet count of $>50 \times 10^{9} / \mathrm{L}$ for dental care; there are no specifications regarding the type of procedure. The treatment options focus on platelet transfusion, because no other obvious options are available and there is no reason to expect a shortened half-life of the platelets in this patient category.

Future research, ideally, should focus on the development of formalized guidelines, for example, based on a Delphi study for which this guideline may serve as a basis or the Grading of Recommendations Assessment, Development and Evaluation (GRADE) approach when more research becomes available. $^{84-88}$

\section{Conclusion}

This systematic review showed a serious lack of available evidence on the management of dentoalveolar procedures in ITP patients, especially for children. Clinically relevant bleeding and infection-related complications after dentoalveolar procedures in ITP patients seemed rare. Prospective studies are needed to further evaluate the safety of dentoalveolar procedures in ITP patients with low platelet counts, as well as the need for and efficacy of therapeutic interventions, to prevent bleeding and/or infections. Awaiting additional evidence to guide the development of evidence-based protocols, we have provided our institutional guideline to guide dental specialists and hematologists in the daily practice of managing dentoalveolar procedures in ITP patients.

\section{What Is Known on This Topic?}

- Dentoalveolar procedures in immune thrombocytopenia (ITP) pose a risk of bleeding, due to thrombocytopenia, and infection, due to immunosuppressive treatments.

- There are currently no guidelines available to support hematologists and dental professionals in the management of dentoalveolar procedures in ITP patients.

\section{What Does This Paper Add?}

- This paper provides an overview of the available evidence regarding the risk of bleeding and infection in ITP, as well as the effectiveness of management strategies.

- To guide health care providers in the management of dentoalveolar procedures in ITP patients despite the limited available evidence, we provide our institutional guidelines.
Conflict of Interest

None declared.

\section{References}

1 Israels S, Schwetz N, Boyar R, McNicol A. Bleeding disorders: characterization, dental considerations and management. J Can Dent Assoc 2006;72(09):827

2 Arnold DM. Bleeding complications in immune thrombocytopenia. Hematology (Am Soc Hematol Educ Program) 2015;2015 (01):237-242

3 Ghoshal K, Bhattacharyya M. Overview of platelet physiology: its hemostatic and nonhemostatic role in disease pathogenesis. ScientificWorldJournal 2014;2014:781857

4 Lambert MP, Gernsheimer TB. Clinical updates in adult immune thrombocytopenia. Blood 2017;129(21):2829-2835

5 Rodeghiero F, Stasi R, Gernsheimer T, et al. Standardization of terminology, definitions and outcome criteria in immune thrombocytopenic purpura of adults and children: report from an international working group. Blood 2009;113(11): 2386-2393

6 Neunert C, Terrell DR, Arnold DM, et al. American Society of Hematology 2019 guidelines for immune thrombocytopenia. Blood Adv 2019;3(23):3829-3866

7 Al-Samkari H, Kuter DJ. Immune thrombocytopenia in adults: modern approaches to diagnosis and treatment. Semin Thromb Hemost 2020;46(03):275-288

8 Hicks SM, Coupland LA, Jahangiri A, Choi PY, Gardiner EE. Novel scientific approaches and future research directions in understanding ITP. Platelets 2020;31(03):315-321

9 Karasneh J, Christoforou J, Walker JS, et al. World Workshop on Oral Medicine VII: Platelet count and platelet transfusion for invasive dental procedures in thrombocytopenic patients: A systematic review. Oral Dis 2019;25(Suppl 1):174-181

10 Iwabuchi H, Imai Y, Asanami S, et al. Evaluation of postextraction bleeding incidence to compare patients receiving and not receiving warfarin therapy: a cross-sectional, multicentre, observational study. BMJ Open 2014;4(12):e005777

11 Wells D, Capes J, Powers M. Complications of dentoalveolar surgery. Oral and Maxillofacial Surgery 2000;1:421-438

12 Lockhart PB, Gibson J, Pond SH, Leitch J. Dental management considerations for the patient with an acquired coagulopathy. Part 1: coagulopathies from systemic disease. Br Dent J 2003;195 (08):439-445

13 Johnson WT, Leary JM. Management of dental patients with bleeding disorders: review and update. Oral Surg Oral Med Oral Pathol 1988;66(03):297-303

14 Malmquist JP. Complications in oral and maxillofacial surgery: management of hemostasis and bleeding disorders in surgical procedures. Oral Maxillofac Surg Clin North Am 2011;23(03): 387-394

15 Portielje JE, Westendorp RG, Kluin-Nelemans HC, Brand A. Morbidity and mortality in adults with idiopathic thrombocytopenic purpura. Blood 2001;97(09):2549-2554

16 Givol N, Goldstein G, Peleg O, et al. Thrombocytopenia and bleeding in dental procedures of patients with Gaucher disease. Haemophilia 2012;18(01):117-121

17 Rebulla P. Platelet transfusion trigger in difficult patients. Transfus Clin Biol 2001;8(03):249-254

18 Hato T, Shimada N, Kurata Y, et al. Risk factors for skin, mucosal, and organ bleeding in adults with primary ITP: a nationwide study in Japan. Blood Adv 2020;4(08):1648-1655

19 Cohen SG. Thrombocytopenia. In: Rose LF, Kaye D, eds. Internal Medicine for Dentistry. Mosby; 1983:425-426, Toronto

20 Webster WP, Roberts HR, Penick GD. Dental care of patients with hereditary disorders of blood coagulation. Mod Treat 1968;5 (01):93-110 
21 British Committee for Standards in Haematology General Haematology Task Force. Guidelines for the investigation and management of idiopathic thrombocytopenic purpura in adults, children and in pregnancy. Br J Haematol 2003;120(04):574-596

22 Estcourt LJ, Birchall J, Allard S, et al; British Committee for Standards in Haematology. Guidelines for the use of platelet transfusions. Br J Haematol 2017;176(03):365-394

23 Franz MG, Steed DL, Robson MC. Optimizing healing of the acute wound by minimizing complications. Curr Probl Surg 2007;44 (11):691-763

24 Guo S, Dipietro LA. Factors affecting wound healing. J Dent Res 2010;89(03):219-229

25 Sonbol H, Pelargidou M, Lucas VS, Gelbier MJ, Mason C, Roberts GJ. Dental health indices and caries-related microflora in children with severe haemophilia. Haemophilia 2001;7(05): 468-474

26 Foster H, Fitzgerald J. Dental disease in children with chronic illness. Arch Dis Child 2005;90(07):703-708

27 Semple JW, Italiano JE Jr, Freedman J. Platelets and the immune continuum. Nat Rev Immunol 2011;11(04):264-274

28 Douketis JD, Berger PB, Dunn AS, et al. The perioperative management of antithrombotic therapy: American College of Chest Physicians evidence-based clinical practice guidelines (8th edition). Chest 2008;133(6, suppl):299S-339S

29 Baudo F, de Cataldo F, Gatti R, Landonio G, Muti G, Scolari G. Local hemostasis after tooth extraction in patients with abnormal hemostatic function. Use of human fibrinogen concentrate. Haemostasis 1985;15(06):402-404

30 Rakocz M, Mazar A, Varon D, Spierer S, Blinder D, Martinowitz U. Dental extractions in patients with bleeding disorders. The use of fibrin glue. Oral Surg Oral Med Oral Pathol 1993;75(03): 280-282

31 Suwannuraks M, Chuansumrit A, Sriudomporn N. The use of fibrin glue as an operative sealant in dental extraction in bleeding disorder patients. Haemophilia 1999;5(02):106-108

32 Bartholomew JR, Salgia R, Bell WR. Control of bleeding in patients with immune and nonimmune thrombocytopenia with aminocaproic acid. Arch Intern Med 1989;149(09): 1959-1961

33 Lee S-T, Kim J-W, Kwon T-G. Life-threating outcomes after dental implantation in patient with idiopathic thrombocytopenic purpura: a case report and review of literature. Maxillofac Plast Reconstr Surg 2018;40(01):39

34 McKelvy B, Satinover F, Sanders B. Idiopathic thrombocytopenic purpura manifesting as gingival hypertrophy: case report. J Periodontol 1976;47(11):661-663

35 Engelen ET, Schutgens RE, Mauser-Bunschoten EP, van Es RJ, van Galen KP. Antifibrinolytic therapy for preventing oral bleeding in people on anticoagulants undergoing minor oral surgery or dental extractions. Cochrane Database Syst Rev 2018;7(07): CD012293

36 Vavricka SR, Walter RB, Irani S, Halter J, Schanz U. Safety of lumbar puncture for adults with acute leukemia and restrictive prophylactic platelet transfusion. Ann Hematol 2003;82(09): 570-573

37 Owattanapanich D, Ungprasert P, Owattanapanich W. Efficacy of local tranexamic acid treatment for prevention of bleeding after dental procedures: a systematic review and meta-analysis. J Dent Sci 2019;14(01):21-26

38 de Vasconcellos Sde A, de Santana Santos T, Reinheimer DM, Faria-E-Silva AL, de Melo MF, Martins-Filho PR. Topical application of tranexamic acid in anticoagulated patients undergoing minor oral surgery: a systematic review and meta-analysis of randomized clinical trials. J Craniomaxillofac Surg 2017;45(01): $20-26$

39 Forbes CD, Barr RD, Reid G, et al. Tranexamic acid in control of haemorrhage after dental extraction in haemophilia and Christmas disease. BMJ 1972;2(5809):311-313
40 van Galen KP, Engelen ET, Mauser-Bunschoten EP, van Es RJ, Schutgens RE. Antifibrinolytic therapy for preventing oral bleeding in patients with haemophilia or von Willebrand disease undergoing minor oral surgery or dental extractions. Cochrane Database Syst Rev 2019;4(04):CD011385

41 Deshayes S, Khellaf M, Zarour A, et al. Long-term safety and efficacy of rituximab in 248 adults with immune thrombocytopenia: results at 5 years from the French prospective registry ITP-ritux. Am J Hematol 2019;94(12):1314-1324

42 Randall KL. Rituximab in autoimmune diseases. Aust Prescr 2016;39(04):131-134

43 Provan D, Butler T, Evangelista ML, Amadori S, Newland AC, Stasi R. Activity and safety profile of low-dose rituximab for the treatment of autoimmune cytopenias in adults. Haematologica 2007;92(12):1695-1698

44 Lo JC, O'Ryan FS, Gordon NP, et al; Predicting Risk of Osteonecrosis of the Jaw with Oral Bisphosphonate Exposure (PROBE) Investigators. Prevalence of osteonecrosis of the jaw in patients with oral bisphosphonate exposure. J Oral Maxillofac Surg 2010; 68(02):243-253

45 Franken AAM, van Blijderveen NJC, Witjes MJH, Netelenbos CJC. Bisfosfonaatgerelateerde osteonecrose van de kaak. Ned Tijdschr Geneeskd 2011;155:A3077

46 Mokhtari DH, Roosendaal G, Koole R, Mauser-Bunschoten EP, van den Berg HM. Bloedige orale ingrepen bij patiënten met hemofilie. Ned Tijdschr Tandheelkd 2003;110:74-77

47 Aldridge E, Cunningham LL Jr. Current thoughts on treatment of patients receiving anticoagulation therapy. J Oral Maxillofac Surg 2010;68(11):2879-2887

48 Douketis JD, Spyropoulos AC, Spencer FA, et al. Perioperative management of antithrombotic therapy: Antithrombotic Therapy and Prevention of Thrombosis, 9th ed: American College of Chest Physicians Evidence-Based Clinical Practice Guidelines. Chest 2012;141(2, suppl):e326S-e350S

49 Fillmore WJ, Leavitt BD, Arce K. Dental extraction in the thrombocytopenic patient is safe and complications are easily managed. J Oral Maxillofac Surg 2013;71(10):1647-1652

50 Tosetto A, Balduini CL, Cattaneo M, et al; Italian Society for Haemostasis and Thrombosis. Management of bleeding and of invasive procedures in patients with platelet disorders and/or thrombocytopenia: Guidelines of the Italian Society for Haemostasis and Thrombosis (SISET). Thromb Res 2009;124(05): e13-e18

51 Arnold DM, Heddle NM, Cook RJ, et al. Perioperative oral eltrombopag versus intravenous immunoglobulin in patients with immune thrombocytopenia: a non-inferiority, multicentre, randomised trial. Lancet Haematol 2020;7(09):e640-e648

52 Marshall AL, Goodarzi K, Kuter DJ. Romiplostim in the management of the thrombocytopenic surgical patient. Transfusion 2015;55(10):2505-2510

53 Ramakrishna R, Rehman A, Ramakrishna S, Alexander W, Yeo WW. Use of romiplostim in patients with chronic idiopathic thrombocytopenic purpura during perioperative period. Intern Med J 2015;45(07):718-724

54 Zaja F, Barcellini W, Cantoni S, et al. Thrombopoietin receptor agonists for preparing adult patients with immune thrombocytopenia to splenectomy: results of a retrospective, observational GIMEMA study. Am J Hematol 2016;91(05):E293-E295

55 Tarantino MD, Fogarty PF, Shah P, Brainsky A. Dental procedures in 24 patients with chronic immune thrombocytopenia in prospective clinical studies of eltrombopag. Platelets 2015;26 (01):93-96

56 Tarantino MD, Bakshi KK, Brainsky A. Hemostatic challenges in patients with chronic immune thrombocytopenia treated with eltrombopag. Platelets 2014;25(01):55-61

57 Landete E, Domingo A, Pérez-Rus G, et al. Perioperative use of eltrombopag in patients with chronic thrombocytopenia. A single-center experience. HemaSphere 2018;2(Suppl 1):1041 
58 Ghanima W, Cooper N, Rodeghiero F, Godeau B, Bussel JB. Thrombopoietin receptor agonists: ten years later. Haematologica 2019;104(06):1112-1123

59 Hsia CC, Liu Y, Eckert K, Monga N, Elia-Pacitti J, Heddle NM. Intravenous immunoglobulin (IVIg) utilization in immune thrombocytopenia (ITP): a multi-center, retrospective review. Drugs Real World Outcomes 2015;2(01):35-42

60 Caress JB, Kennedy BL, Eickman KD. Safety of intravenous immunoglobulin treatment. Expert Opin Drug Saf 2010;9(06): 971-979

61 Ramírez E, Romero-Garrido JA, López-Granados E, et al. Symptomatic thromboembolic events in patients treated with intravenous-immunoglobulins: results from a retrospective cohort study. Thromb Res 2014;133(06):1045-1051

62 Provan D, Stasi R, Newland AC, et al. International consensus report on the investigation and management of primary immune thrombocytopenia. Blood 2010;115(02):168-186

63 Padmore RF. Hemolysis upon intravenous immunoglobulin transfusion. Transfus Apheresis Sci 2012;46(01):93-96

64 Bharath V, Eckert K, Kang M, Chin-Yee IH, Hsia CC. Incidence and natural history of intravenous immunoglobulin-induced aseptic meningitis: a retrospective review at a single tertiary care center. Transfusion 2015;55(11):2597-2605

65 Hamrock DJ. Adverse events associated with intravenous immunoglobulin therapy. Int Immunopharmacol 2006;6(04):535-542

66 Bonilla FA. Intravenous immunoglobulin: adverse reactions and management. J Allergy Clin Immunol 2008;122(06):1238-1239

67 Cherin P, Marie I, Michallet M, et al. Management of adverse events in the treatment of patients with immunoglobulin therapy: a review of evidence. Autoimmun Rev 2016;15(01):71-81

68 Mohamed M. Intravenous immunoglobulin-associated hemolysis: risk factors, challenges, and solutions. Int J Clin Transfus Med. 2016;4:121-131

69 Daniel GW, Menis M, Sridhar G, et al. Immune globulins and thrombotic adverse events as recorded in a large administrative database in 2008 through 2010. Transfusion 2012;52(10): 2113-2121

70 Godeau B, Caulier M-T, Decuypere L, Rose C, Schaeffer A, Bierling P. Intravenous immunoglobulin for adults with autoimmune thrombocytopenic purpura: results of a randomized trial comparing 0.5 and $1 \mathrm{~g} / \mathrm{kg}$ b.w. Br J Haematol 1999;107(04):716-719

71 Godeau B, Chevret S, Varet B, et al; French ATIP Study Group. Intravenous immunoglobulin or high-dose methylprednisolone, with or without oral prednisone, for adults with untreated severe autoimmune thrombocytopenic purpura: a randomised, multicentre trial. Lancet 2002;359(9300):23-29

72 Min KH, Rhee C-K, Jung JY, Suh M-W. Characteristics of adverse effects when using high dose short term steroid regimen. Korean J Audiol 2012;16(02):65-70

73 Kyle V, Hazleman BL. Treatment of polymyalgia rheumatica and giant cell arteritis. II. Relation between steroid dose and steroid associated side effects. Ann Rheum Dis 1989;48(08):662-666

74 Broadbent C, Pfeffer P, Steed L, Walker S. Patient-reported side effects of oral corticosteroids. Eur Respir J 2018;52:3144

75 Zorginstituut Nederland. Farmacotherapeutisch Kompas. Accessed September 28, 2021 at: https://farmacotherapeutischkompas.nl

76 Waljee AK, Rogers MAM, Lin P, et al. Short term use of oral corticosteroids and related harms among adults in the United States: population based cohort study. BMJ 2017;357:j1415

77 Salama A, Kiesewetter H, Kalus U, Movassaghi K, Meyer O. Massive platelet transfusion is a rapidly effective emergency treatment in patients with refractory autoimmune thrombocytopenia. Thromb Haemost 2008;100(05):762-765

78 Gibson N, Ferguson JW. Steroid cover for dental patients on longterm steroid medication: proposed clinical guidelines based upon a critical review of the literature. Br Dent J 2004;197 (11):681-685
79 Cronberg S, Wallmark E, Söderberg IS CEffect on platelet aggregation of oral administration of 10 non-steroidal analgesics to humans. Scand J Haematol 1984;33(02):155-159

80 Schafer AI. Effects of nonsteroidal antiinflammatory drugs on platelet function and systemic hemostasis. J Clin Pharmacol 1995;35(03):209-219

81 Goldenberg NA, Jacobson L, Manco-Johnson MJ. Brief communication: duration of platelet dysfunction after a 7-day course of Ibuprofen. Ann Intern Med 2005;142(07):506-509

82 Ruggiero SL, Dodson TB, Fantasia J, et al; American Association of Oral and Maxillofacial Surgeons. American Association of Oral and Maxillofacial Surgeons position paper on medication-related osteonecrosis of the jaw-2014 update. J Oral Maxillofac Surg 2014;72(10):1938-1956

83 Abed H, Alhabshi M, Alkhayal Z, Burke M, Nizarali N. Oral and dental management of people with myelodysplastic syndromes and acute myeloid leukemia: a systematic search and evidencebased clinical guidance. Spec Care Dentist 2019;39(04):406-420

84 Alonso-Coello P, Oxman AD, Moberg J, et al; GRADE Working Group. GRADE evidence to decision (EtD) frameworks: a systematic and transparent approach to making well informed healthcare choices. 2: clinical practice guidelines. BMJ 2016; 353:i2089

85 Atkins D, Eccles M, Flottorp S, et al; GRADE Working Group. Systems for grading the quality of evidence and the strength of recommendations I: critical appraisal of existing approaches the GRADE working group. BMC Health Serv Res 2004;4(01):38

86 Guyatt G, Oxman AD, Akl EA, et al. GRADE guidelines: 1. Introduction-GRADE evidence profiles and summary of findings tables. J Clin Epidemiol 2011;64(04):383-394

87 Guyatt GH, Oxman AD, Vist GE, et al; GRADE Working Group. GRADE: an emerging consensus on rating quality of evidence and strength of recommendations. BMJ 2008;336 (7650):924-926

88 Schünemann HJ, Mustafa R, Brozek J, et al; GRADE Working Group. GRADE Guidelines: 16. GRADE evidence to decision frameworks for tests in clinical practice and public health. J Clin Epidemiol 2016;76:89-98

89 Finucane D, Fleming P, Smith O. Dentoalveolar trauma in a patient with chronic idiopathic thrombocytopenic purpura: a case report. Pediatr Dent 2004;26(04):352-354

90 Guzeldemir E. The role of oral hygiene in a patient with idiopathic thrombocytopenic purpura. Int J Dent Hyg 2009;7(04): 289-293

91 Harms RE, Cornelissen JJ, Visch LL. Orthodontic tooth extraction in a patient with idiopathic thrombocytopenia [in Dutch]. Ned Tijdschr Tandheelkd 1996;103(03):92-93

92 Inchingolo F, Crincoli V, Dipalma G, Inchingolo AM. Patient at high hemorrhagic risk. Surgical management of three cases and review of the literature. Minerva Stomatol 2005;54(04): 247-253

93 Larionova E, Tarasenko S, Morozova E, Diachkova E. Use of erbium laser in the treatment of a patient with acute purulent periostitis and a resistant form of primary immune thrombocytopenia. Case Rep Dent 2019;2019:8260605

94 Martin AA, Manton SL, Kerr R. Case reports: extraction of teeth in patients with primary immune thrombocytopenia using the drug eltrombopag. J Disabil Oral Heal. 2013;14(03): 111-113

95 Oda Y, Kagami H, Tohnai I, Ueda M. Asynchronously occurring bilateral mandibular hemorrhagic bone cysts in a patient with idiopathic thrombocytopenic purpura. J Oral Maxillofac Surg 2002;60(01):95-99

96 Sangwan A, Tewari S, Narula SC, Sharma RK, Sangwan P. Significance of periodontal health in primary immune thrombocytopenia- a case report and review of literature. J Dent (Tehran) 2013;10(02):197-202 
97 Tay S, Szabo F, Spain B. Dental extraction in a child with chronic idiopathic thrombocytopenia purpura: are preoperative platelet transfusions necessary? A A Case Rep 2013;1(01):3-4

98 Vaisman B, Medina AC, Ramirez G. Dental treatment for children with chronic idiopathic thrombocytopaenic purpura: a report of two cases. Int J Paediatr Dent 2004;14(05):355-362

99 Heidbuchel H, Verhamme P, Alings M, et al. Updated European Heart Rhythm Association Practical Guide on the use of non-vitamin $\mathrm{K}$ antagonist anticoagulants in patients with non-valvular atrial fibrillation. Europace 2015;17(10): 1467-1507

100 Madrid C, Sanz M. What influence do anticoagulants have on oral implant therapy? A systematic review. Clin Oral Implants Res 2009;20(Suppl 4):96-106

101 Oliver RJ, Sloan P, Pemberton MN. Oral biopsies: methods and applications. Br Dent J 2004;196(06):329-333, quiz 362 